\title{
Defeat Depression Campaign
}

\section{Attitudes towards depression: some medical anthropological queries}

\author{
Sushrut Jadhav and Roland Littlewood
}

The vigorous public profile adopted by the College in the 'Defeat Depression' campaign (Psychiatric Bulletin, 1993, 17, 573-574) is to be welcomed, but the proposed educational programme is premature. The MORI poll is not an adequate basis for understanding how 'depression' is popularly conceived nor how people respond to it. The research report (Royal College of Psychiatrists, 1992) says little about the methods used in the qualitative part of the study: whether the researchers were properly trained in ethnographic field interviewing to elicit illness categorisations, and their ability to elicit the whole complex of ideas and actions, involving nomenclature, causation, agency, recognition and recourse to treatment.

The main thrust of the campaign is to popularise the biomedical concept of depression (i.e. 'what depression is': page 573), one which we already know is rather different from lay usage of the term or its cognates (Kleinman \& Good. 1985). Yet the College's qualitative and quantitative studies both use a propositional approach which starts with the presentation of the word 'depression'. Such an approach is inevitably constrained by the elicitation of discrete statements. Critics of this method have argued that such statements are obviously restricted to attitudes that are a product of the item in the proposition as popularly understood, not the patterns understood by professionals as included in the category (White, 1982). More significantly, it has been recognised for some years that simplistic attitudinal surveys also fail to capture the full complexity of local illness conceptualisations which generally involve unstable, heterogenous and contradictory categories dependent on immediate context, and which deeply overlap with other elicited categories, are explained through multiple causalities, and which may be quite unrelated to actual pragmatic decisions (White, 1982; Littlewood, 1990). Such decisions are themselves oriented, not to a discrete lexical item like 'depression', but to more diffuse sociallyembedded patterns of action (Holy \& Stuchlik, 1980).
For example, if a subject's notions of attribution reveal three core constructs for depression let us say, unemployment, marital difficulties and physical weakness - these may be related causally to each other in quite different nonlinear modes (Jadhav, 1992). We can only make sense of this in relation to a particular society's core notions of the self, moral agency and intentionality; not only to its elicited lexicon of affect, but to its categorical logic and contingent recourse to therapy. Unless these complex pathways are understood, it is unlikely we will be able to change 'attitudes'.

At a basic level, a simple propositional approach misses the categorical semantics (White, 1982). We have just analysed the first 1220 responses in a cross-cultural 11 country study on stigmatisation of severe mental illness; this uses a brief clinical vignette (without a named category) developed in three languages (Bengali. English and Sinhalese), through ethnographic pilot studies in five countries (Britain, India, Sri Lanka, South Africa and Trinidad). Respondents were asked to give a name that might best identify the illness described in the vignette. Taking the English language responses alone $(n=892)$, we find 140 different terms offered for the pattern of illness described in one vignette alone (and these responses included such diverse suggestions as 'mad', 'normal', 'illumination', 'depression', 'neurosis', 'mental retardation', 'cancer' and 'mania'). The vignette was a lay description of severe mental illness, recognised by most of the psychiatrist respondents as schizophrenia, but which in turn was derived from popular descriptions of illness in Britain. India and Sri Lanka. With a vignette based on 'depression' (which is not only a biomedical disease entity but also a lay account of everyday distress), one would expect even more categories to be elicited. What the MORI poll has not shown is how patterns of distress may be popularly recognised (and perhaps categorised) but are not locally regarded as 'depression' although they would be by biomedical categorisation; and the point of the educational programme is 
presumably to have these patterns relabelled and responded to as 'depression'. However, those of our respondents $(n=31)$ who did label our 'severe mental illness' vignette as 'depression' were more likely to offer stigmatising responses to the vignette than the other respondents on 14 of our measures of stigmatisation, with less stigmatising conceptions on only nine (and one equal).

What other lay categories overlap with 'depression'? And how? Is the term used in similar ways for what we (as psychiatrists) would term dysthymia and clinical disease? What is its semantic network, those other meanings which it connotes and evokes? (Kleinman \& Good, 1985). Does 'depression' entail characteristic patterns of personal responsibility and attribution? What is the logical structure of the elicited ideas? How stable, how contingent are they? We are not necessarily arguing for a proper ethnographic study (although the effort which is to be put into the educational campaign might warrant this). There are avallable a number of rigorous ethnographically-derived instruments such as the Explanatory Model Interview Catalogue (Weiss et al, 1992) which could have furnished precisely this information.

An extensive literature is available on popular illness categorisations and health-related behaviours - the subject matter of medical anthropology - including major conceptual studies on 'depression' (Kleinman \& Good, 1985). We are concerned that the College has placed so much conviction in a restricted public opinion survey in a way that might have seemed immediately plausible at the policy level, but which ignores the current evidence in favour of the sort of rather easier but practically limited attitudinal studies once popular in the United States. We are even more concerned that the College seems to recommend this as the appropriate way to go about research into categorisations of illness. To then mount a glossy educational campaign on the basis of this method is frankly disturbing; research in other public health domains such as leprosy shows that attempts to educate the public simply by inculcating professional medical models (supposedly 'less stigmatising' - and that is another question) do not necessarily bring about reduced stigmatisation or improved compliance (Weiss et al, 1992).

To understand those responses we term 'stigma', and how they function, we need to start from two different methodological approaches the biomedical and the ethnographic - without predicating the one on the other (Littlewood, 1990). Only then may some sort of meeting point emerge and help clinicians incorporate patients' own models of illness as relevant clinical information (Kleinman, 1987).

\section{References}

Holy, L. \& STUCHLIK, M. (1980) The Structure of Folk Models, London: Academic Press.

JADHAV. S.S. (1992) Adapting the EMIC to study depressed British subjects. Abstracts, XII World Congress of Soctal Psychiatry, New Delhi.

KLEINMAN, A. (1987) Anthropology and psychiatry: The role of culture in cross-cultural research on ilness. British Journal of Psychiatry, 161, 447-454.

- \& GoOD, B. (eds) (1985) Culture and Depression: Studies in the Anthropology and Cross-Cultural Psychiatry of Affect and Disorder. Berkeley: California University Press.

LTTTLEWOOD, R. (1990) From categories to contexts: a decade of the 'new cross-cultural psychiatry'. British Journal of Psychiatry, 156, 308-327.

ROYAL COLLEGE OF PSYCHIATRISTS (1992) Research study conducted for the 'Defeat of Depression' campalgn, ms: Royal College of Psychiatrists.

WeISS, M., DoongAJ, D. et al (1992) The explanatory model interview catalogue (EMIC): a contribution to crosscultural research methods from a study of leprosy and mental health. Brittsh Journal of Psychiatry, 160, 819830.

WHITE, G.M. (1982) The ethnographic study of cultural knowledge of 'mental disorder'. In Cultural Conceptions of Mental Health and Therapy (eds. G.M. White and A.J. Marsella) Dordrecht: Reidel.

Sushrut Jadhav, Lecturer, and Roland Littlewood, Professor, Centre for Medical Anthropology, Departments of Psychiatry and Anthropology. University College London, WC1E 6BT

\section{Response from Professor R.G. Priest}

Jadhav \& Littlewood make some interesting and thoughtful points, but I cannot agree with some of their syllogisms. I certainly do not sympathise with the pejorative tone of their comments ("to mount a glossy [sic] campaign ... is frankly disturbing") nor accept what appears to be their principal conclusion that "the proposed educational programme is premature". 